\title{
Movement disorders emergencies: a review
}

\author{
Emergências em distúrbios do movimento: uma revisão \\ Renato P. Munhoz'1,2, Mariana Moscovich'1, Patrícia DareAraujo', Hélio A. G. Teive²
}

\begin{abstract}
Movement disorders (MD) encompass acute and chronic diseases characterized by involuntary movements and/or loss of control or efficiency in voluntary movements. In this review, we covered situations in which the main manifestations are MDs that pose significant risks for acute morbidity and mortality. The authors examine literature data on the most relevant MD emergencies, including those related to Parkinson`s disease, acute drug reactions (acute dystonia, neuroleptic malignant syndrome, serotonergic syndrome and malignant hyperthermia), acute exacerbation of chronic MD (status dystonicus), hemiballism and stiff-person syndrome, highlighting clinical presentation, demographics, diagnosis and management.
\end{abstract}

Key words: movements disorders, dystonia, neuroleptic malignant syndrome, serotonergic syndrome, malignant hyperthermia, status dystonicus, dyskinesias, stiff person syndrome.

\section{RESUMO}

Os distúrbios do movimento (DM) englobam doenças agudas e crônicas caracterizadas por movimentos involuntários e/ou perda do controle ou eficiência em movimentos voluntários. Nesta revisão, incluímos situações nas quais as principais manifestações são DM que representam risco devido à alta morbidade e mortalidade. Os autores revisaram aspectos relacionados às principais emergências em DM, incluindo aquelas relacionadas a doença de Parkinson; reações causadas por drogas (distonia aguda, síndrome neuroléptica maligna, síndrome serotoninérgica, hipertermia maligna); exacerbação aguda de DM crônicos (status distonicus); hemibalismo e síndrome da pessoa rígida. São destacados a apresentação clínica, os dados demográficos, o diagnóstico e o tratamento.

Palavras-Chave: distúrbios de movimentos, distonia, síndrome maligna neuroléptica, síndrome serotoninérgica, hipetermia maligna, status distonicus, discinesias, síndrome da pessoa rígida.

Movement disorders (MD) encompass disorders characterized by involuntary movements and/or loss of control or efficiency in voluntary movement ${ }^{1}$. Patients with MD usually have disabling symptoms; however, most cases are followed and treated in ambulatory care settings. A MD emergency is defined as a neurological disorder evolving acutely or subacutely, in which the clinical presentation is dominated by $\mathrm{MD}$ and in which failure to accurately diagnose and manage the patient may result in significant morbidity or even mortality ${ }^{1}$. In this review, we used these criteria to divide MD emergencies into six main topics.

I. Emergencies in Parkinson's disease (PD)
a. Severe motor fluctuations and the super OFF phenomenon
b. Parkinsonism-hyperpyrexia and dyskinesia-hyperpy- rexia syndromes
c. Acute parkinsonism
d. Acute psychosis in Parkinson's disease

II. Acute drug reactions
a. Acute dystonia
b. Neuroleptic malignant syndrome
c. Serotonergic syndrome
d. Malignant hyperthermia

III. Acute exacerbation of chronic MDs
a. Status dystonicus
b. Neurological and orthopedic complications of dysto- nia and pseudodystonia
c. Laryngeal dystonia in multiple system atrophy and other conditions
d. Tic status and neurological complications of tics
e. Wilson's disease emergencies
f. Others conditions

IV. Acute chorea and hemiballism-hemichorea

V. Stiff-person syndrome

VI. Lethal catatonia

${ }^{1}$ Department of Neurology, Pontifical Catholic University of Paraná (PUCPR), Curitiba PR, Brazil;

${ }^{2}$ Movement Disorders Unit, Neurology Service, Internal Medicine Department, Federal University of Paraná (UFPR), Curitiba PR, Brazil. Correspondence: Renato P. Munhoz; Avenida Sete de Setembro 4698/1507; 80240-000 Curitiba PR - Brasil; E-mail: renatopuppi@gmail.com Conflict of interest: There is no conflict of interest to declare.

Received 14 January 2012; Received in final form 27 January 2012; Accepted 06 February 2012 


\section{EMERGENCIES IN PARKINSON'S DISEASE (PD)}

\section{a. Severe motor fluctuations and the super OFF phenomenon}

Motor fluctuations (MF) develop in 70\% of Parkinson's disease patients treated with levodopa for nine years or longer and in nearly all patients with early onset PD after less than ten years of treatment ${ }^{2}$. The definition of MF is closely related to the definition of ON and OFF periods: an ON period is the time of levodopa responsiveness, with adequate control of motor symptoms, while an OFF period is the time when parkinsonian symptoms are significantly present. Both usually correlate directly or indirectly with levodopa plasma levels, however the mechanisms that lead to MF are complex and involve the reduction of striatal synthesis and storage of dopamine from exogenous levodopa and subsensitization of postsynaptic dopaminergic receptors ${ }^{2}$. The "wearing off" phenomenon describes the presence of end dose OFF periods, mainly due to the loss of stratial dopamine storage capacity and short levodopa half-life ${ }^{2}$. The ON-OFF phenomenon and unpredictable OFFs describe the occurrence of sudden and disabling OFF periods with no clear relationship with timing of levodopa intake. The "delayed ON" (increased time latencies from dose intake to the start-up of an ON period) and "no-ON" phenomenon (complete failure of a levodopa dose to exert an $\mathrm{ON}$ response) are typically related to impaired absorption of oral levodopa ${ }^{2}$.

In rare instances, $\mathrm{MF}$ can represent a $\mathrm{MD}$ emergency, especially in the case of frequent and distressful ON-OFF periods. Typically, management involves various combined approaches, such as administration of small multiple daily doses of levodopa, controlled release, dispersible and soluble levodopa formulations, subcutaneous dopamine agonists, MAO-B and COMT inhibitors, and surgical approaches. Administration of crushed levodopa tablets may also be helpful in certain circumstances².

The "super OFF" phenomenon is a rare complication found in patients with PD defined as an increase in motor disability scores in comparison to basal (OFF period) motor scores described in those experiencing $\mathrm{MF}^{3}$. As the denomination implies, it means that patients affected by this phenomenon have the sensation of being more symptomatic from most parkinsonian motor standpoints than their usual OFF levodopa dose status. The super OFF state can be divided into a beginning-of-dose and an end-of-dose inhibitory effect, depending on whether it occurs before or after levodopa has reached a therapeutic plasma concentration ${ }^{4}$. The phenomenon is often very distressing and disabling, lasting from minutes to hours. The pathophysiology of super OFF episodes is not entirely clear, but is probably linked either to presynaptic inhibition of firing and release of dopaminergic neurons, or an effect mediated by the preferential stimulation of a subpopulation of postsynaptic DA receptors that have an inhibitory action on motor activity caused by low levels of levodopa in the rising or declining phase of the plasma concentration curve ${ }^{3}$. Gershanik et al. ${ }^{4}$ reported a reduction in the severity of super OFF phenomenon in patients treated with clozapine, while Dziewczapolski et al. ${ }^{3}$ found the same beneficial effects of clozapine in an animal model of parkinsonism. These authors speculate on the possibility that clozapine could inhibit the inhibitory action of low plasma levodopa levels, leading to an apparent antiparkinsonian effect. Another study ${ }^{5}$ explored the pathophysiology of super OFF episodes by examining the effects of subthreshold, threshold and suprathreshold infusions of apomorphine in a randomized, double-blind, placebo controlled, crossover study. They concluded that these episodes may be present only in certain subgroups of PD patients. They also suggested that the main mechanism involved is not likely to be a presynaptic or autoreceptor effect of dopaminergic agents, thus leaving the possibility of a post synaptic cause ${ }^{5}$.

\section{b. Parkinsonism-hyperpyrexia and dyskinesia- hyperpyrexia syndromes}

Parkinsonism-hyperpyrexia syndrome (PHS), also known as neuroleptic malignant-like syndrome, is a rare complication of $\mathrm{PD}^{6}$, characterized by hyperthermia, autonomic dysfunction, altered consciousness, severe rigidity and elevated serum creatine kinase (CK) levels. PHS may be triggered by infections, reduction in dopaminergic drug dosage, hot weather or dehydration. Potentially life-threatening complications include deep venous thrombosis and pulmonary embolism, aspiration pneumonia and renal failure. Treatment is based on intravenous fluids infusion, antithermics and use of levodopa and dopamine agonists. Occasionally, dantrolene may be necessary.

Another MD emergency related to PD, recently designated dyskinesia-hyperpyrexia syndrome ${ }^{7}$, consists of severe dyskinesias (dyskinetic status), leading to muscle exhaustion, rhabdomyolysis, hyperthermia and confusion. This complication shares some of the clinical characteristics of PHS, but differs in those dyskinesias - instead of rigidity, dominates the clinical picture. Additionally, the dyskinesia-hyperpyrexia syndrome, contrarily to PHS, should be treated by reducing the dosage of dopaminergic drugs, particularly dopamine agonists.

\section{c. Acute parkinsonism}

Acute severe de novo parkinsonism is an uncommon form of parkinsonism that occurs over hours or days. In general, the most frequent cause is exposure to dopamine-blocking agents, such as neuroleptics and anti-emetics, however other rare causes have been described, including hypoxic-ischemic encephalopathy, intoxications (organophosphate pesticide, carbon monoxide and drugs used for cancer therapy, as cytosine arabinoside, cyclophosphamide and amphotericin) and infections (viruses-similar to Von Economós encephalitis lethargic, Japanese B encephalitis and neurocysticercosis) ${ }^{1,8,9}$. 
Acute worsening of motor symptoms in patients with PD may also occur independently of disease progression. This situation typically occurs due to additional medical conditions, as urinary or respiratory infections and metabolic disturbances (hypothyroidism and so on), or even due to a concomitant neurological disease, for example, subdural hematomas, compressive spinal cord lesion or brain tumor ${ }^{8,10}$. Treatment of both de novo and worsening of PD should be focused on resolution of the etiologic process and occasionally symptomatic treatment of parkinsonism using dopaminergic agents ${ }^{11}$.

\section{d. Acute psychosis in Parkinson's disease}

Psychosis is relatively common among advanced PD patients, often associated with some degree of cognitive dysfunction. The acute occurrence of psychosis is frequently associated and triggered by the same agents used to treat the motor symptoms of PD (levodopa, dopamine agonists, anticholinergics, amantadine, COMT and MAO-B inhibitors), however other comorbidities, such as infections (urinary and respiratory tract), metabolic or neurological disturbances, may play a role ${ }^{10,11}$. The manifestations typically include visual hallucinations, persecutory delusions, confusion and psychomotor agitation. After treatment of potential comorbidities, management recommendations begin with the stepwise withdrawal of potentially associated drugs, starting with anticholinergics, followed by MAO-B inhibitors, dopamine agonists, amantadine and COMT inhibitors. Frequently, the introduction of a second generation antipsychotic,as clozapine or quetiapine, is necessary. Other options include risperidone or olanzapine, with a significant risk of motor symptoms worsening ${ }^{8,11}$.

\section{ACUTE DRUG REACTIONS}

\section{a. Acute dystonia}

By definition, dystonia is characterized by involuntary sustained muscle contractions, frequently causing twisting and repetitive movements or abnormal postures ${ }^{12}$. While dystonias can be classified as focal, segmental, multifocal, hemidystonia or generalized, their etiologies are typically defined as primary (including genetic forms and idiopathic) or secondary.

Drug induced acute dystonia (DID) is one of the commonest forms of secondary dystonia, along with tardive dystonia. This complication occurs in wide frequency range, depending on the specific drugs prescribed, indications and studied populations ${ }^{13,14}$. The causative drugs are commonly antidopaminergic, not restricted to the "classic" neuroleptics, including haloperidol, risperidone, olanzapine and antiemetics ${ }^{15}$. Less frequently, other drug classes, such as anticonvulsants and antidepressants, are involved in this type of complication. The contractions can occur immediately after ingestion of a single dose, over the course of several days of therapeutic doses administration, after dose increase or as a manifestation of overdosage $\mathrm{e}^{15}$. Most cases occur in the first 72 hours of medication use with often dramatic symptoms, especially in children ${ }^{15}$. Patients at higher risk for DID include those with a younger age, of male gender, a previous history of similar reactions, recent use of cocaine, comorbidity with mood disorders and metabolic abnormalities (hypokalemia, dehydration, hypoparathyroidism, etc $)^{13,14}$.

Clinical presentation commonly includes craniocervical distribution with blepharospasm, bucolinguomandibular, face and neck dystonia, and oculogyric crisis with contracture of the extraocular muscles leading to conjugate eyes deviation, usually with a predominance of the superior rectus muscle and consequent upward eye deviation. A peculiar form of drug-induced acute dystonia is laryngeal spasm due to dystonia of vocal cords related muscles (laryngospasm), leading to acute upper airway obstruction. Appendicular symptoms tend to be more common among elderly patients. Typically, symptoms and signs are action induced, following treatment initiation or dose increase ${ }^{14,16}$.

Finally, tardive dyskinesias may became a MD emergency, particularly in the cases of severe respiratory/diaphragmatic dyskinesias and the case of so-called "withdrawal-emergent” dyskinesias (severe dyskinesias after withdrawal from neuroleptics) ${ }^{8}$.

Table 1 shows the clinical manifestations of acute dystonia according to the affected muscle group.

The differential diagnoses of acute dystonia include other neurological and systemic disorders, such as partial seizures, meningitis, tetanus, electrolyte disturbances and strychnine poisoning. The treatment options include intramuscular or intravenous anticholinergics (e.g., biperiden $5 \mathrm{mg}$ IV, followed by PO maintenance for up to seven days). Alternatively, or in milder cases, promethazine $50 \mathrm{mg}$ IM may be effective. Oculogyric crisis usually improves significantly with clonazepam $2 \mathrm{mg}$ PO or diphenhydramine 25 or $50 \mathrm{mg}$ IM. "Prophylaxis" with anticholinergics or amantadine is controversial and should not be routinely used ${ }^{1,8,12,15-18}$.

\section{b. Neuroleptic malignant syndrome}

Neuroleptic malignant syndrome (NMS) is an idiosyncratic abrupt reaction to antidopaminergic drug treatment with characteristic clinical and paraclinical findings ${ }^{19,20}$. Classically, the causative agents include the "classic" neuroleptics, however after the widespread use of newer agents, the "atypical” agents have also been implicated ${ }^{21}$. Additionally, NMS has been described during treatment with other dopamineblocking drugs or after abrupt withdrawal of dopaminergic agents $^{1,8,9,11,22,23}$.

Typically, symptoms onset occurs during the first two weeks of treatment initiation or change of dose. A number of factors are believed to increase the risk of NMS, including abrupt starting or dose escalation, depot formulations, 
Table 1. Clinical manifestations of acute dystonia according to the affected muscle group.

\begin{tabular}{|c|c|c|}
\hline Affected area & Manifestation & Clinical symptoms \\
\hline Eyelid & Blepharospasm & Eyelid closure \\
\hline $\begin{array}{l}\text { Facial, larynx, jaw, } \\
\text { tongue }\end{array}$ & Bucolingual crises & $\begin{array}{l}\text { Repetitive chewing, } \\
\text { swallowing and } \\
\text { gagging, facial } \\
\text { asymmetry, trismus }\end{array}$ \\
\hline Extraocular & Oculogyric crisis & $\begin{array}{l}\text { Conjugate eye } \\
\text { deviation }\end{array}$ \\
\hline Larynx and pharynx & Larynx dystonia & Dystonia, stridor \\
\hline Cervical & Torticollis & $\begin{array}{l}\text { Cervical spasm or } \\
\text { spasmodic, lateral } \\
\text { deviation of head }\end{array}$ \\
\hline Paravertebral & Opisthotonus & Trunk hyperextension \\
\hline
\end{tabular}

male gender, young age, concomitant use of lithium and selective serotonine reuptake inhibitors (SSRIs), high ambient temperatures, hyponatremia, dehydration, physical exhaustion, mental retardation, extrapyramidal syndromes, psychomotor agitation and a previous episode of $\mathrm{NMS}^{24}$. NMS occurs in all age groups, from 9 months to 78 years, with mean ages around the fourth and fifth decades across studies ${ }^{20-24}$. Mortality remains relatively high, varying from 20 to $30 \%$ of cases $^{20-22}$. Most cases that survive acute NMS recover without sequelae; however, some patients remain with cognitive deficits and motor abnormalities, including rigidity, tremor and dystonic contractures ${ }^{25}$.

Diagnostic criteria include the tetrad of hyperthermia, rigidity, altered mental status and dysautonomia. These main findings can be associated with other signs such as action and/or rest tremor, dystonia, chorea, myoclonus, seizures, ataxia, hyporeflexia and extensor plantar reflexes ${ }^{19,20}$. Additionally, NMS may be associated with laboratory changes that include raised serum CK (>1000 IU/L), impaired liver, renal and coagulation status tests, leukocytosis, electrolyte disturbances, proteinuria and rhabdomyolysis with myoglobinuria ${ }^{20-22}$. The most important differential diagnoses in most cases are serotonergic syndrome, malignant hyperthermia and malignant catatonia ${ }^{20-25}$. Also, sudden withdrawal of intrathecal baclofen, used for the treatment of spasticity, can lead to an acute syndrome similar to $\mathrm{NMS}^{1}$.

Clinical approaches to treatment involve early recognition, exclusion of the differential diagnoses, medication withdrawal and pharmacological and nonpharmacological interventions $^{22-24}$. The choice of these later is mainly determined by the severity of NMS and the presence of additional complications. Supportive care includes correction of volume and electrolyte imbalance, prevention of infection, thrombosis and pressure ulcers, and body cooling. Patients with severe symptoms often require management in an intensive care facility ${ }^{24}$.

Pharmacological interventions should be focused on reducing muscle rigidity with, for example, benzodiazepines or dantrolene; reversing the hypothesized excessive dopaminergic blockade using bromocriptine, levodopa or amantadine; and controlling agitation ${ }^{22,26}$. Electroconvulsive therapy (ECT) has been used in selected cases $^{27}$. Finally, patients should be withdrawn of neuroleptics for, at least, two weeks after the termination of management of the acute phase of NMS before treatment of the background psychiatric condition can be restarted ${ }^{19}$. This should be done with low doses, slow titration, avoiding concomitant use of lithium, and close observation to prevent dehydration and the initial symptoms of NMS.

\section{c. Serotonergic syndrome}

Serotonin syndrome (SS) is a potentially fatal disorder that results most often from the combined use of two or more agents that enhance serotonin activity or concentration in the central nervous system ${ }^{1,9,11,12,28}$. This under recognized syndrome is usually manifested by acute development of agitation, mental status changes, myoclonus, incoordination, postural instability, hyperreflexia, rigidity and dysautonomic features (diaphoresis, fever, diarrhea, tachycardia and hemodynamic instability) after a change in serotonergic drug regimen ${ }^{29}$. The most commonly used diagnostic criteria require at least three of these clinical features after other possible causes have been excluded, as discussed in detail below. Although onset is typically abrupt, some patients report insidious or recurrent symptoms of subtle cognitive decline, behavioral abnormalities and tremor with mild postural disorders days to weeks before the full-blown syndrome develops ${ }^{29-31}$.

SS is not an idiosyncratic reaction, but a predictable one. In theory, the offending drugs or, more often, the combination of drugs are those that cause excessive brainstem and spinal cord serotonin or 5-hydroxytryptamine type 1A receptor (5-HT1A) stimulation ${ }^{30,31}$. Evidence of pathophysiologic roles for 5-HT2 and possibly 5-HT3 subtypes have also been speculated ${ }^{30,32}$. The implicated agents listed in previous reviews include inhibitors of serotonin reuptake (SSRIs, tricyclic antidepressants, dextromethorphan, amphetamine and cocaine), inhibitors of serotonin metabolism (monoamine oxidase inhibitors [MAOIs]), serotonin precursors (L-tryptophan), enhancers of serotonin release (amphetamines, cocaine, fenfluramine), serotonin agonists (risperidone, sumatriptan, ergotamines) and nonspecific enhancers of serotonin activity, as lithium and electroconvulsive therapy $^{29-33}$. Any of these agents alone can potentially cause SS, however a combination is usually needed, with greater risk for patients using MAOIs or SSRIs concomitantly with any other serotonergic agent ${ }^{30}$. Although doses taken are usually within therapeutic limits, almost $20 \%$ of the cases reviewed presented after medication overdose $\mathrm{e}^{30-32,34}$. Other circumstances in which these agents may cause SS include rapid dose titration, addition or switch to a new agent without a proper washout period, liver or renal disease, endogenously 
reduced monoamine oxidase A activity (e.g., primary enzyme deficit, chronic schizophrenia, certain personality disorders), cytochrome P450 2D6 enzyme inhibition and old age ${ }^{32}$.

The prevalence and incidence of SS is largely unknown, however it is probably increasing mirroring the wide use of serotonergic agents in medical practice for various purpos$\mathrm{es}^{29}$. As serum or cerebrospinal fluid (CSF) serotonin levels are useless for the diagnosis of SS, diagnosis is established on clinical grounds ${ }^{30,31}$. The starting point is obviously a history of exposure to agents that direct or indirectly interfere with the serotonergic system. Additionally, a number of clinical manifestations are required: altered mental status, autonomic instability and motor abnormalities, including tremor, myoclonus, gait and appendicular ataxia, hyperreflexia and muscle rigidity. Seizures, renal failure and disseminated intravascular coagulopathy have also been described in more severe cases $^{28-30,33}$. Finally, laboratory abnormalities include metabolic acidosis, rhabdomyolysis, elevated serum aminotransferase, creatinine levels and white blood cell count. The most widely used and validated diagnostic criterion is the Hunter Serotonin Toxicity Criteria ${ }^{34}$ that includes the use of a serotonergic agent plus any of the following: (i) myoclonus, agitation or diaphoresis; (ii) tremor and hyperreflexia; (iii) hypertonia; (iv) temperature above 38 degrees Celsius. Also, other possible causes have to be ruled out, including infections, other forms of intoxication, metabolic and hormonal abnormalities, and drug withdrawal. Some symptoms of SS can mimic those due to an overdose of cocaine or lithium ${ }^{30-34}$. Other differential diagnoses include anticholinergic poisoning, malignant hyperthermia and NMS, each of these readily distinguished from SS based on medication exposure history ${ }^{29,30,34}$.

The key principles for successful treatment are prevention, early detection and acute intervention. Withdrawal of the offending agents is the mainstay of therapy, enough to control signs and symptoms in almost half of all cases ${ }^{30,34}$. For persistent or severe symptoms, specific pharmacologic treatment may be necessary. Although the role of theoretically specific therapy is still uncertain and possibly does not have a direct impact on survival, it may reduce symptoms duration $^{33}$. Nonspecific 5-HT receptor blockers, such as cyproheptadine and methysergide, have their use documented by several case reports and have been credited with shortening the syndrome's duration and with preventing the onset of experimentally induced SS in animals ${ }^{32,33,35}$. Other potential therapeutic agents include benzodiazepines, chlorpromazine and propranolol ${ }^{28,29,33}$. Supportive measures include treatment of seizures, cardiac arrhythmias, disseminated intravascular coagulation, muscle rigidity and hyperthermia ${ }^{33}$. Prognosis is generally good, provided early recognition, and adequate management occurs. In previous reports and reviews, morbidity has not been formally assessed, and mortality rates ranged from 2.4 to $12 \%$, with the caveat that these data represent series of known patients with $\mathrm{SS}^{29,30}$. After recovery, cautious reintroduction of a serotonergic agent may be necessary, with close observation of symptoms and signs. It is also essential for clinicians to be reminded that, in general, these agents must be started at the lowest efficacious dose with slow titration, especially in the elderly, in whom polypharmacy is unavoidable ${ }^{28,31}$.

\section{d. Malignant hyperthermia}

Malignant hyperthermia (MH) is a rare, potentially fatal complex genetic disorder of skeletal muscle that occurs when a patient with an inherited $\mathrm{MH}$-susceptible mutation is exposed to triggering anesthetic agents ${ }^{1,36-38}$. $\mathrm{MH}$ usually manifests as a hypermetabolic crisis characterized by rapid onset of hyperthermia, fluctuations in blood pressure, hypercarbia, hyperkalemia, metabolic acidosis, muscle rigidity and rhabdomyolysis. The episodes are usually associated with the administration of inhalation anesthetics or depolarizing muscle relaxants ${ }^{36,37}$.

The clinical syndrome results from uncontrolled calcium flux across skeletal muscle membrane, and in more than half of affected families an autosomal dominant linkage to a gene encoding a skeletal muscle intracellular $\mathrm{Ca}^{2+}$ release channel receptor (type 1 ryanodine receptor) is detected ${ }^{38}$. Treatment with dantrolene is effective, combined with discontinuation of the triggering agents and correction of metabolic and electrolyte abnormalities ${ }^{37}$. In the 1970s, mortality was greater than $80 \%$, however with the current management and diagnostic awareness, mortality is less than $5 \%^{37,38}$.

A comparison of features and management of NMS, SS and MH is presented in Table 2.

\section{ACUTE EXACERBATION OF CHRONIC MDS}

\section{a. Status dystonicus}

Status dystonicus (SD), or dystonic storm, is a life threatening condition associated with both primary and secondary dystonia. SD was first recognized by Jankovic and Penn ${ }^{39}$ in 1982 and is defined as “(...) increasingly frequent and severe episodes of generalized dystonia, which necessitate urgent hospital admission". These episodes are usually refractory to traditional pharmacological therapy and may be triggered by trauma, surgery, infection, fever and abrupt introduction, withdrawal or change in medical treatment, including lithium, tetrabenazine and clonazepam ${ }^{40-42}$. The muscle contractures are painful, interfering with respiratory function and causing metabolic complications as hyperpyrexia, dehydration, respiratory insufficiency, rhabdomyolysis and acute renal failure. SD is rare and no definitive consensus exists regarding the ideal treatment strategy that most often include a combination of several drugs and even surgical interventions ${ }^{40-42}$. Most reported cases required prompt therapeutic intervention with adequate fluid balance, analgesia, antipyretics, ventilatory support and hemodynamic monitoring, including 
Table 2. Comparison of features and management of neuroleptic malignant syndrome, serotonergic syndrome and malignant hyperthermia.

\begin{tabular}{|c|c|c|c|}
\hline & NMS & SS & $\mathrm{MH}$ \\
\hline Age/gender & Young males & No predisposition & Children, young adults \\
\hline Triggering factor & Idiosyncratic & Dose related & Genetic \\
\hline Fever & ++ & ++ & +++ \\
\hline Confusion & +++ & +++ & + \\
\hline Dysautonomia & +++ & +++ & +++ \\
\hline Motor features & Tremor, rigidity & Myoclonus, stereotypies, hyperreflexia & - \\
\hline Diaphoresis & ++ & ++ & +++ \\
\hline Elevated CK & +++ & ++ & +++ \\
\hline Metabolic acidosis & + & + & ++ \\
\hline Causative agents & $\begin{array}{l}\text { Classic and newer antipsychotics, } \\
\text { antiemetics, levodopa withdrawal }\end{array}$ & SSRIs, SNRIs, TAs, MAOIs & $\begin{array}{l}\text { Volatile anesthetics, } \\
\text { succinylcholine }\end{array}$ \\
\hline Pharmacologic treatment* & Bromocriptine, amantadine, dantrolene, ECT & Cyproheptadine, Methylsergide & Dantrolene, Azumolene \\
\hline Criteria & Levenson JL, 1985 & Dunkley EJ, 2003 & Larach MG, 1994 \\
\hline
\end{tabular}

NMS: neuroleptic malignant syndrome; SS: serotonergic syndrome; MH: malignant hyperthermia; CK: serum creatine kinase levels; SSRIs: selective serotonin reuptake inhibitors;SNRIs: serotonin-norepinephrine inhibitors; TAs: tricyclic antidepressants; MAOls: monoamine oxidase inhibitors; ECT: electroconvulsive therapy.

* Prior to any form of pharmacological treatment, patients should be stabilized and withdrawn from causative agent.

admission in intensive care units to avoid metabolic, renal and ventilatory complications.

As the specific pharmacological substrate of dystonia is ill defined, to date, treatment of SD is mainly empirical and variable. Agents used in previous case series and reports include tetrabenazine, baclofen, chlormethiazole, anticholinergics (benzhexol and biperiden), dopamine receptor blockers (haloperidol and pimozide), anticonvulsants (carbamazepine, primidone and valproic acid), levodopa, acetazolamide, benzodiazepines (midazolan, clonazepam and diazepam), deep sedation with propofol, barbiturate anesthesia and muscle blockers ${ }^{39-42}$. These drugs were used in anecdotal reports as combinations with variable efficacy, often requiring additional interventions, for example, continuous infusion of intrathecal baclofen and stereotactic surgery (thalamotomy, pallidotomy or DBS electrodes placement). As already outlined, SD is a potentially life threatening complication and its course and outcome is highly variable, including cases with complete remission, deterioration of clinical condition and death ${ }^{40-42}$.

\section{b. Neurological and orthopedic complications of dystonia and pseudodystonia}

Severe dystonic contractures, particularly in generalized dystonia, may lead neurological and orthopedic complications, including spinal cord compression (particularly cervical myelopathy) and even lesions to nervous plexi or peripheral nerves. From an orthopedic standpoint, patients with severe generalized dystonia may also develop severe and disabling scoliosis ${ }^{8,43,44}$.

The term pseudodystonia encompasses conditions that mimic dystonia, including some that may present acute or subacutely, including infectious and neoplastic torticollis, atlantoaxial rotatory subluxation and localized tetanus.
Infectious torticollis as known as Grisel's syndrome may be secondary to pharyngitis, tonsillitis or retropharyngeal $\operatorname{abscess}^{1,8,9,17}$.

\section{c. Laryngeal dystonia in multiple system atrophy and other conditions}

Multiple system atrophy (MSA) is a form of atypical parkinsonism characterized by the presence of a MD (either parkinsonism or cerebellar ataxia) and dysautonomia. Some of these patients may present developed disturbing and potentially dangerous laryngeal stridor, predominantly during the night, with an increased risk of sudden death due to upper airway obstruction ${ }^{1,8}$. This complication is caused by posterior cricoarytenoid muscles dysfunction (which abduct the vocal cords), either by dystonia or paresis.

Acute laryngeal dystonia may also be a very rare form of task-specific dystonia (Gerhardt's syndrome), in which the affected individual presents spasm of the adductor muscles of the vocal cord during inspiration but while performing other activities, such as speaking. Clinically patients developed severe stridor with risk of upper airway obstruction. Immediate treatment with intravenous diphenhydramine $(25 \mathrm{mg}$ to 50 $\mathrm{mg}$ ) is effective in most cases. Occasionally, tracheostomy or even botulinum toxin injection is necessary $y^{1,8,10,16,17}$.

\section{d. Tic status and neurological complications of tics}

Patients with chronic motor, vocal tics or Tourette's syndrome may present with continuous disabling tics that cannot be suppressed, interfering dramatically with daily life activities and leading to cardiorespiratory difficulties, autonomic signs and even rhabdomyolysis ${ }^{45}$. This condition is known as tic status and represents a rare MD emergency. Triggering factors described in the literature include withdrawal of drugs used to treat tics (e.g., haloperidol or 
clonidine), mycoplasma infection and extreme reactive stress $^{45}$. Treatment includes readministration of previously withdrawn drug, dosage increase of previous therapy, addition of benzodiazepines or switching to second generation antipsychotics. Also, discontinuation of agents know to induce tics, such as methylphenidate, is essential. Botulinum toxin injections may be particularly helpful in patients with malignant vocal tics or coprolalia ${ }^{8,16,45}$.

Finally, occasional patients may have motor tics that, similar to dystonia and other hyperkinetic MD, may cause neurological complications like cervical myelopathy in the case of violent neck motor tics $8,17,45$.

\section{e. Wilson's disease emergencies}

Wilson's disease (WD) is an autosomal recessive disease of copper metabolism caused by mutations in the ATP7B gene. The most common neurologic symptoms are tremor, dysarthria, dystonia, ataxia and parkinsonism. Emergencies in WD are related to hepatic involvement ( fatal acute or fulminant liver failure) or sudden worsening of neurological symptoms, particularly after use of D-penicillamine ${ }^{8}$.

\section{f. Others conditions}

Other several clinical conditions that can present as MD emergencies include hypocalcemia, tetanus, rabies and strychnine toxicity ${ }^{1}$. Tetanic muscle spasm can develop secondary to hypocalcemia. Tetanus, caused by the exotoxin tetanopasmin, produced by the anaerobic bacterium Clostridium tetani, presents traditionally with muscle spasms (triggered by touch, visual, auditory stimuli), stiffness, autonomic instability and respiratory insufficiency. Management in intensive care unit involves the use of tetanus immune globulin, benzodiazepines and ventilatory support. Rabies and strychnine toxicity represent a rare form of infection and toxic causes of MD emergencies ${ }^{1}$.

\section{ACUTE CHOREA AND HEMIBALLISM- HEMICHOREA}

Hemiballism is a relatively rare hyperkinetic disorder, characterized by irregular, wide amplitude, vigorous involuntary movements of the limbs, primarily due to involuntary activity of the proximal limb and associated axial muscles ${ }^{46}$. Ballism is considered a very severe form of chorea, in which the movements have a violent, flinging quality. The term derives from the Greek word ballismos, which means "jumping about or dancing." This MD most often involves one side of the body, but, occasionally, bilateral movements occur, a condition then defined as biballism ${ }^{46-48}$. The most consistent neuropathological finding in hemiballism is a lesion of the contralateral subthalamic nucleus (STN), usually of vascular origin $^{49}$. However, lesions in different locations are not uncommon, including the ipsilateral STN, caudate nucleus, putamen, thalamus, substantia nigra, and the premotor and motor cortex ${ }^{50}$. Also, other causes have been described, as metabolic disorders (nonketotic hyperglycemia, hypoglycemia, hyperthyroidism), Sydenham's chorea (chorea insatiens), systemic lupus erythematosus/antiphospholipid syndrome, post-operative period of cardiac surgery with extracorporeal circulation (post-pump chorea), infectious diseases of the central nervous system (e.g., human immunodeficiency virus infection, toxoplasmosis, syphilis, abscess), tumors and multiple sclerosis ${ }^{47-49}$. Frequently, hemiballism is associated to hemichorea and, then, the term hemiballism-hemichorea (HBC) is used to describe this clinical spectrum ${ }^{48,49}$.

A particular form of $\mathrm{HBC}$ associated to nonketotic hyperglycemia was described by Lin and Chang ${ }^{51}$ in three diabetic patients. In two of them, the hyperkinesia was the initial presenting symptom of diabetes. Soon after this description, Lee et al. ${ }^{52}$ reported on eight female diabetic patients with HB-HC, further characterizing the clinical syndrome with magnetic resonance imaging (MRI) correlation (contralateral high signal intensity putaminal lesion without edema or swelling on T1-weighted MRI). Finally, Mestre et al. ${ }^{53}$ presented the pathological correlate of the imaging findings, defining that putaminal petechial haemorrhages in a fatal case of nonketotic hyperglycemia chorea.

Prognosis is benign in most cases. Mild chorea often does not require treatment; however, when the hyperkinetic movements are of sufficient severity to cause functional disability and exhaustion, several different approaches have been advocated ${ }^{47,50-54}$. A combination of a benzodiazepine with either haloperidol, olanzapine or tetrabenazine, titrated over days to maintain a balance between control of the movement disorder and side effects, such as sedation, can be effective $^{47,50,51}$. Other options include gabapentin, valproic ac$\mathrm{id}^{55}$, and, as a last resort, stereotactic surgery ${ }^{51}$.

\section{Stiff-person syndrome}

Stiff person syndrome (SPS) is a rare neurological disorder characterized by the presence of fluctuating muscle rigidity and spasms of the trunk and more proximal body parts $^{56-58}$. Patients with SPS may present as an emergency with severe pain and spasms of the lumbar paraspinal muscles and lower limbs. The spasms, often associated with intense pain, typically begin with an abrupt jerk followed by tonic activity that slowly subsides over seconds to, less commonly, minutes ${ }^{56,57}$. Rarely, these spasms last days (status spasticus) ${ }^{58}$. The affected muscles are typically extremely hard to palpation with a board-like appearance, leading to hyperlordosis ${ }^{56}$. Muscle spasms can occur spontaneously or be provoked by noise or movement. The spasms may be so forceful as to produce femoral fractures, joint subluxations and even herniation of abdominal contents. Paroxysmal autonomic dysfunctions, such as transient hyperpyrexia, diaphoresis, tachypnea, tachycardia, pupillary dilation and arterial hypertension, are recognized. Rhabdomyolysis can 
be a potential complication of the excessive muscle contractions in SPS. Sudden death can also occur due to an acute autonomic failure ${ }^{56}$. In a significant number of cases, SPS is believed to be mediated by autoantibodies to glutamic acid decarboxylase (anti-GAD) ${ }^{56,57}$ that limit the gamma amino-butyric acid (GABA) neuronal activity and lower the threshold for muscle spasms, other neurologic and psychiatric features of the disorder. SPS with elevated serum antiGAD levels may occur with other autoimmune disorders, including diabetes mellitus, Graves' disease, Hashimoto's thyroiditis and pernicious anemia. Ten percent of cases with normal levels of this antibody may be related to autoantibodies against amphiphysin which commonly represent a paraneoplastic syndrome related to breast cancer, mediastinal tumors, small cell lung cancer, Hodgkin's disease and colon cancer ${ }^{56}$.

The management of SPS is based on the use of drugs that promote GABAergic inhibition, for example, benzodiazepines (diazepam and clonazepam) and baclofen ${ }^{56,57}$. Highdose benzodiazepines can abolish the excessive motor unit activity. Oral baclofen provides relatively modest relief, while intrathecal administration seems to be much more effective. Finally, variable degrees of benefit have been reported with the use of antiepileptic drugs, such as valproic acid, levetiracetam and gabapentin ${ }^{56-58}$.

\section{Lethal catatonia}

Lethal or malignant catatonia (MC) is an uncommon and probably under-recognized clinical syndrome that usually occurs in the setting of schizophrenia, but may also follow infections as meningitis and encephalitis, head trauma, drug intoxication and metabolic disturbances, for example, uremia, porphyria and Wernicke's encephalopathy ${ }^{1,59}$. The diagnosis is clinical, and no paraclinical tests confirm the specific diagnosis. Also, little is known about its pathophysiology ${ }^{59}$. From a clinical standpoint, MC is characterized by hyperthermia, autonomic instability and severe rigidity, which, if prolonged, can be followed by exhaustion, coma, renal failure, cardiovascular collapse and death. Violent behavior, including unprovoked assaults and suicide attempts, may occur occasionally ${ }^{1}$. Although MC differs from NMS by the severity of the behavioral abnormalities in the early stages, both syndromes may become indistinguishable in their more advanced stages ${ }^{59}$.

Other differential diagnoses include non-psychiatric stupor, encephalopathy, locked-in syndrome, malignant hyperthermia, nonconvulsive status epilepticus or autism ${ }^{59}$. Treatment includes high dose intravenous benzodiazepines, barbiturates and $\mathrm{ECT}^{1 .}$ Other interventions, such as dantrolene, bromocriptine, amantadine and anticonvulsants (e.g., carbamazepine), may have some utility ${ }^{59}$.

\section{References}

1. Kipps CM, Fung VSC, Grattan-Smith P, de Moore GM, Morris JGL. Movement disorder emergencies. Mov Disord 2005;20:322-334.

2. Melamed E, Ziv I, Djaldetti R. Management of motor complications in advanced Parkinson's disease. Mov Disord 2007;22(Suppl):S379-384.

3. Dziewczapolski G, Menalled LB, Savino MT, Mora M, Stefano FJE, Gershanik O. Mechanism of action of clozapine-induced modification of motor behavior in an animal model of the 'super-off' phenomenon. Mov Disord 1997;12:159-166.

4. Gershanik O, Lera G, Gomez Arevalo G. Clinical profile of parkinsonian patients with super off phenomenon. Neurology 1994;44:248.

5. Gunzler SA, Koudelka C, Carlson NE, Pavel M, Nutt JG. Effect of low concentrations of apomorphine on parkinsonism in a randomized, placebo-controlled, crossover study. Arch Neurol 2008;65:193-198.

6. Mizuno Y, Takubo H, Mizuta E, Kuno S. Malignant syndrome in Parkinson's disease:conceptand review of the literature. Parkinsonism Relat Disord 2003;9:S3-S9.

7. Gil-Navarro S, Grandas F. Dyskinesia-hyperpyrexia syndrome: another Parkinson's disease emergency. Mov Disord 2010;25:2691-2692.

8. Poston KL, Frucht SJ. Movement disorders emergencies. J Neurol 2008;255:S2-S13.

9. Sá DS, Teive HA, Troiano AR, Werneck LC. Parkinsonism associated with neurocysticercosis. Parkinsonism Relat Disord 2005;11:69-72.

10. Robottom BJ, Weiner WJ, Factor SA. Movement disorders emergencies part 1. Hypokinetic disorders. Arch Neurol 2011;68:567-572.

11. Tousi B. Movement disorder emergencies in the elderly: recognizing and treating an often-iatrogenic problem. Cleve Clin $\mathrm{J}$ Med 2008;75:449-457.

12. Fahn S. Medical treatment of dystonia. In: Tsui JKC, Calne DB (eds). Handbook of dystonia. New York: Marcel Dekker; 1995:317-328.
13. Fabiani G, Teive HA, Germiniani F, Sá D, Werneck LC. Clinical and therapeutical features in 135 patients with dystonia: experience of movement disorders unity of the Hospital de Clínicas of the Universidade Federal do Paraná. Arq Neuropsiquiatr 1999;57:610614.

14. Casey DE. Neuroleptic-induced acute dystonia. In: Lang AE (Ed). DrugInduced movement disorders. Mount Kisco: Futura Publishing Co; 1992:21-41.

15. Barreira R, Magaldi RB. Acute dystonia after use of bromopride in pediatric patients. Rev Paul Pediatr 2009;27:110-114.

16. Robottom BJ, Factor SA, Weiner WJ. Movement disorders emergencies part 2. Hyperkinetic disorders. Arch Neurol 2011;68:719-724.

17. Frucht SJ. Hyperkinetic movement disorders emergencies. American Academy of Neurology. Minneapolis: Sillabus; 2002.

18. Miyasaki JM, Lang AE. Treatment of drug-induced movement disorders. In: Kurlan R (Ed). Treatment of movement disorders. Philadelphia: Lippincott; 1995:429-474.

19. Levenson JL. Neuroleptic malignant syndrome. AM J Psychiatry 1985;142:113.

20. Henderson VW, Wooten GF. Neuroleptic malignant syndrome: a pathogenic role for dopamine receptor blockade? Neurology 1981;31:132-137.

21. Moscovich M, Nóvak FT, Fernandes AF, et al. Neuroleptic malignant syndrome. Arq Neuropsiquiatr 2011;69:751-755.

22. Trollor JN, Chen X, Sachdev SP. Neuroleptic malignant syndrome associated with atypical antipsychotic drugs. CNS Drugs 2009;23: 477-492.

23. Rosebush PI, Garside S, Mazurek MF. Recognizing neuroleptic malignant syndrome. CMAJ 2004;170:1645. 
24. Berardi D, Dell'Atti M, Amore M, De Ronchi D, Ferrari G. Clinical risk factors for neuroleptic malignant syndrome. Hum Psychopharmacol 2002;17:99-102.

25. Levinson DF, Simpson G. Sequelae of neuroleptic malignant syndrome. Biol Psychiatry 1987;22:273-278.

26. Rosebush PI, Stewart T, Mazurek MF. The treatment of neuroleptic malignant syndrome. Are dantrole and bromocriptine useful adjuncts to supportive care? Br J Psychiatry 1991;159:709-712.

27. Trollor JN, Sachdev PS. Electroconvulsive treatment of neuroleptic malignant syndrome: a review and report of cases. Aus NZJ Psychiatry 1999;33:650-659.

28. Sternbach H. The serotonin syndrome. Am J Psychiatry 1991;148: 705-713.

29. Boyer EW, Shannon M. The serotonin syndrome. N Engl J Med 2005; 352:1112-1120.

30. Lane R, Baldwin D. Selective serotonin reuptake inhibitor-induced serotonin syndrome: review. J Clin Psychopharmacol 1997;17:208221.

31. Munhoz RP. Serotonin syndrome Induced by a combination of bupropion and SSRIs. Clin Neuropharmacol 2004;27:219-222.

32. Turkel SB, Nadala JG, Wincor MZ. Possible serotonin syndrome in association with 5-HT(3) antagonist agents. Psychosomatics 2001;42:258-260.

33. Ables AZ, Nagubilli R. Prevention, recognition, and management of serotonin syndrome. Am Fam Physician 2010;81:1139-1142.

34. Dunkley EJ, Isbister GK, Sibbritt D, Dawson AH, Whyte IM. The Hunter Serotonin Toxicity Criteria: simple and accurate diagnostic decision rules for serotonin toxicity. QJM 2003;96:635-642.

35. Graudins A, Stearman A, Chan B. Treatment of the serotonin syndrome with cyproheptadine. J Emerg Med 1998;16:615-619.

36. Saidman W, Havard ES, Eger El. Hyperthermia during anesthesia. JAMA 1964;190:1029-1032.

37. Ali SZ, Taguchi A, Rosenberg H. Malignant hyperthermia. Best Pract Res Clin Anaesthesiol 2003;17:519-533.

38. Mathews KD, Moore SA. Multiminicore myopathy, central core disease, malignant hyperthermia susceptibility, and RYR1 mutations: one disease with many faces? Arch Neurol 2004;61:27-29

39. Jankovic J, Penn AS. Severe dystonia and myoglobinuria. Neurology 1982;32:1195-1197.

40. Mariotti P, Fasano A, Contrarino MF, et al. Management of status dystonicus: our experience and review of the literature. Mov Disord 2007;22:963-968.

41. Manji H, Howard RS, Miller DH, et al. Status dystonicus: the syndrome and its management. Brain 1998;121:243-252
42. Teive HA, Munhoz RP, Souza MM, et al. Status dystonicus: study of five cases. Arq Neuropsiquiatr 2005;63:26-29.

43. Teive HA, Sá DS, Grande CV, Antoniuk A, Werneck LC. Bilateral pallidotomy for generalized dystonia. Arq Neuropsiquiatr 2001 59:353-357.

44. Spitz M, Gonçalves L, Silveira L, Barbosa ER. Myelopathy as a complication of cervical dystonia. Mov Disord 2006;21:726-735

45. Krauss JK, Jankovic J. Severe motor tics causing cervical myelopathy in Tourette's syndrome. Mov Disord 1996;11:563-566.

46. Shannon KM. Ballism. In: Jankovic J, Tolosa E (Eds). Parkinson's disease and movement disorders. 3 ed., Baltimore: Williams and Wilkins; 1998:365-375.

47. Coral P, Teive HAG, Werneck LC. Hemibalismo: relato de oito casos. Ara Neuropsiquiatr 2000;58:698-703.

48. Dewey RB, Jankovic J. Hemiballism-hemichorea. Clinical and pharmacologic findings in 21 patients. Arch Neurol 1989;46:862-867.

49. Whittier JR. Ballism and the subthalamic nucleus (nucleus hypothalamicus; corpus Luysi) review of the literature and study of 30 cases. Arch Neurol Psychiatry 1947;58:672-692.

50. Lang AE. Persistent hemiballismus with lesions outside the subthalamic nucleus. Can J Neurol Sci 1985;12:125-128.

51. Lin JJ, Chang MK. Hemiballism-hemichorea and non-ketotic hyperglycemia.J Neurol Neurosurg Psychiatry 1994;57:748-750.

52. Lee BC, Hwang SH, Chang GY. Hemiballismus-hemochorea in older women: A clinical syndrome with MRI correlation. Neurology 1999;52:646-648.

53. Mestre TA, Ferreira JJ, Pimentel J. Putaminal petechia haemorrahage as the cause of non-ketotic hyperglycaemic chorea: a neuropathological case correlated with MRI findings. J Neurol Neurosurg Psychiatry 2007;78:549-550.

54. Zétola VF, Verschoor B, Lima FM, et al. Hemibalismo-hemicoréia em estado hiperglicêmico não cetótico: distúrbio do movimento associado ao diabete melito. Arq Bras Endocrinol Metab 2010:54:335-338.

55. Sethi KD, Patel BP. Inconsistent response to divalproex sodium in hemichorea/hemiballism. Neurology 1990;40:1630-1631.

56. Espay AJ, Chen R. Rigidity and spasms from autoimmune encephalomyelopathies: stiff-person syndrome. Muscle Nerve 2006:34:677-690.

57. Munhoz RP, Fameli H, Teive HA. Stiff person syndrome as the initial manifestation of systemic lupus erythematosus. Mov Disord 2010;25:516-517.

58. Brown P, Marsden CD. The stiff man and stiff man plus syndromes. $J$ Neurol 1999;246:648-652.

59. Bhati MT, Datto CJ, O'Reardon JP. Clinical manifestations, diagnosis, and empirical treatments for catatonia. Psychiatry 2007;4:46-52. 